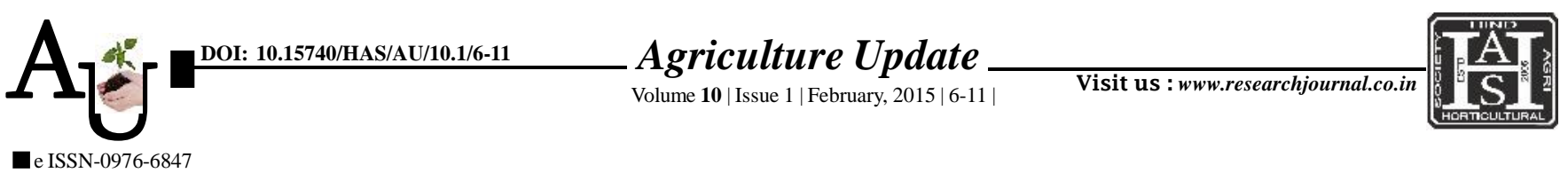

\title{
Research Article: Knowledge and adoption of production technology by ajwain growers
}

Article Chronicle : Received : 14.08.2014;

Revised : 17.12.2014;

Accepted :

03.01.2015

\section{G.B. MORE*, S.U. MOKHALE AND N.J. CHIKHALE}

SUMMARY : The present research study was conducted on 100 ajwain growers from 10 villages comprising 5 villages each from Akot and Telhara tahasils of Akola district of Vidarbha region of Maharashtra state to ascertain the knowledge possessed and adoption level of farmers about recommended cultivation practices of ajwain. The result revealed that near about cent per cent of respondents had high knowledge of cultivation practices recommended for ajwain likewise; soil type, seed rate and sowing type, sowing time, spacing, weed management and intercultural operation, time of harvesting and stage of harvesting whereas minimum knowledge about recommended varieties $(27.0 \%)$, seed treatment $(17.0 \%)$, plant protection $(33.0 \%)$, fertilizer application $(13.0 \%)$. Likewise, majority of respondent (85.0\%) were included under medium level of adoption. As regard to finding of relational analysis revealed that out of ten characteristics studied age, education, area under ajwain crop, irrigation facilities, social participation, sources of information and scientific orientation, were positively and significantly correlated with knowledge and adoption. Likewise, land holding was positively and significantly correlated only with knowledge and non-significantly correlated with adoption. Whereas, annual income was non-significantly correlated with both knowledge and adoption.

How to cite this article : More, G.B., Mokhale, S.U. and Chikhale, N.J. (2015). Knowledge and adoption of production technology by ajwain growers. Agric. Update, 10(1): 6-11.
Key Words :

Knowledge, Adoption, Ajwain, Correlation
Author for correspondence :

\section{G.B. MORE}

College of Horticulture, Dr. Panjabrao Deshmukh

Krishi Vidyapeeth, AKOLA (M.S.) INDIA

See end of the article for authors' affiliations 